\title{
T-cell acute lymphoblastic leukemia with co-expression of CD56, CD34, CD117 and CD33: A case with poor prognosis
}

\author{
RAFET EREN, CEYDA ASLAN, OSMAN YOKUŞ, MEHMET HILMI DOĞU and ELIF SUYANI \\ Department of Hematology, Istanbul Training and Research Hospital, Fatih, 34098 Istanbul, Turkey
}

Received March 5, 2016; Accepted May 20, 2016

DOI: $10.3892 / \mathrm{mco} .2016 .927$

\begin{abstract}
T-cell acute lymphoblastic leukemia (ALL) is an aggressive hematological malignancy, accounting for $\sim 25 \%$ of all adult cases of ALL. We herein report a case of T-cell ALL exhibiting aberrant CD34, CD56, CD33 and CD117 expression in addition to T-cell markers, which did not respond to induction treatment. A 55-year-old woman was admitted to our hospital with a sore throat unresponsive to medication for 1 month. The laboratory examination revealed pancytopenia and the peripheral blood smear examination revealed blast cells. On flow cytometric analysis, the blast cells were found to be positive for cytoplasmic CD3, CD2, CD5, CD7, CD34, CD56, CD33 and CD117, and negative for myeloperoxidase, CD13, CD11b, CD15, CD19, CD79a, CD22 and CD10. The patient was diagnosed with T-cell ALL according to the 2008 World Health Organisation classification. The patient did not respond to Hyper-cyclophosphamide, vincristine, adriamycin and dexamethasone (CVAD) course A treatment and succumbed to the disease during Hyper-CVAD course $\mathrm{B}$ treatment. To the best of our knowledge, this is the first report of aberrant co-expression of the natural killer cell marker CD56, myeloid cell markers CD117 and CD33 and stem cell marker CD34 in a patient with T-cell ALL. This appears to be associated with an unfavorable outcome, despite the use of intensive chemotherapy.
\end{abstract}

\section{Introduction}

T-cell acute lymphoblastic leukemia (ALL), which is an aggressive hematological malignancy occurring as a consequence of malignant transformation of T-cell progenitors, accounts for $25 \%$ of all adult cases of ALL $(1,2)$. Although CD1a, CD2, CD3 (membranous as well as cytoplasmic), CD4, CD5, CD7 and CD8 are all T-cell antigens, cytoplasmic $\mathrm{CD} 3$ is considered as an indicator of T-cell lineage (2). In

Correspondence to: Dr Elif Suyani, Department of Hematology, Istanbul Training and Research Hospital, Kasap İlyas Mah. Org. Abdurrahman Nafiz Gürman Cd., Fatih, 34098 Istanbul, Turkey E-mail: elifsuyani@hotmail.com

Key words: T-cell acute lymphoblastic leukemia, CD56, CD34, CD117, CD33 addition to T-cell markers, myeloid-associated antigens CD33, CD117 (2-4), CD34 (2,5) and CD56 (6,7) have been found to be expressed by blasts in T-cell ALL. However, concomitant expression of all these markers in the same patient has not been previously reported.

We herein present a case of T-cell ALL exhibiting aberrant expression of CD34, CD56, CD33 and CD117, in addition to T-cell markers, which did not respond to induction treatment.

\section{Case report}

A 55-year-old woman was admitted to our hospital with a sore throat unresponsive to medication for 1 month. On physical examination, the tonsils and oropharynx were found to be hyperemic, without any other remarkable findings. The laboratory tests revealed a hemoglobin level of $9.1 \mathrm{~g} / \mathrm{dl}$, platelet count of $1.95 \times 10^{9} / 1$, leukocyte count of $1.97 \times 10^{9} / 1$ and lactate dehydrogenase level of $205 \mathrm{U} / 1$. The peripheral blood smear examination revealed blast cells. Bone marrow biopsy and aspiration were performed. The bone marrow aspiration showed hand mirror-shaped blast cells (Fig. 1). On conventional cytogenetic study, there was no metaphase for assessment. On flow cytometric analysis, the blast cells were found to be positive for cytoplasmic CD3, CD2, CD5, CD7, CD34, CD56, CD33 and $\mathrm{CD} 117$, whereas they were negative for myeloperoxidase, CD13, CD11b, CD15, CD19, CD79a, CD22 and CD10 (Fig. 2). The patient was diagnosed with T-cell ALL according to the World Health Organisation 2008 criteria (8), and was administered cyclophosphamide, vincristine, adriamycin and dexamethasone (hyper-CVAD 1A) therapy. After the first cycle of treatment, bone marrow aspiration revealed $10 \%$ blast cells. Therefore, methotrexate and cytarabine (hyper-CVAD 1B) treatment was initiated. On the 18th day of therapy, the patient deteriorated clinically and subsequently developed septic shock. The patient was intubated and admitted to the intensive care unit; however, she succumbed to the disease on day 20 of the hyper-CVAD 1B treatment.

\section{Discussion}

Although T-cell ALL develops due to malignant transformation of T-cell progenitors, aberrant myeloid marker expression on blast cells, particularly of CD13, CD33 and rarely CD117, has been previously described (2-4). In myeloid antigen-expressing T-cell ALL patients, the frequency of 


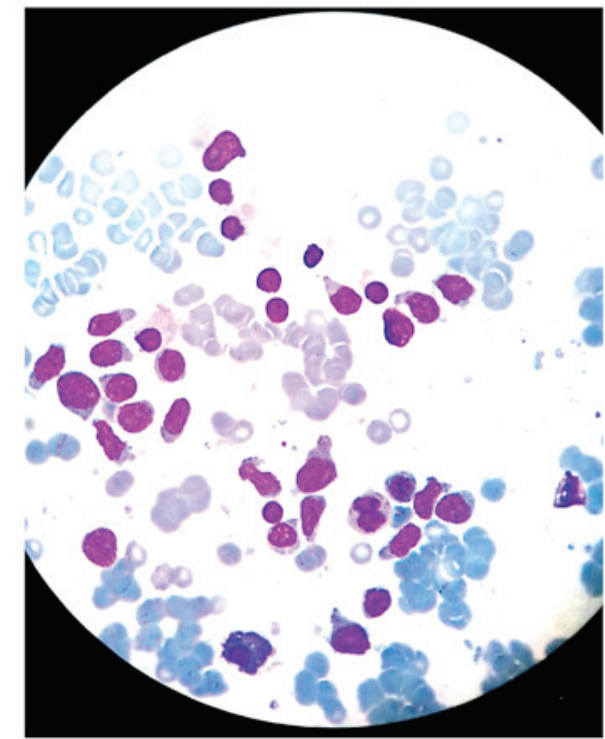

Figure 1. Hand mirror-shaped blast cells on examination of bone marrow aspirate.
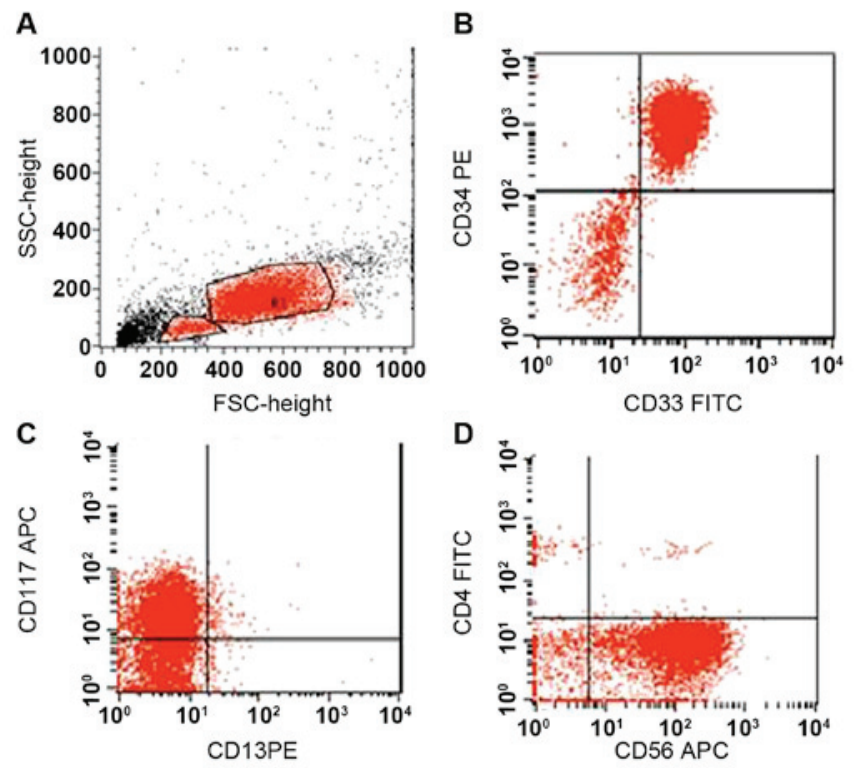

Figure 2. (A) Gating of blast cells on forward scatter (FSC) and side scatter (SSC) light plots; (B) CD33- and CD34-positive blast cells; (C) CD117-positive blast cells; and (D) CD56-positive blast cells.

CD34 expression, a transmembrane glycoprotein that is expressed on hematopoietic stem cells and early thymic T-cell precursors (9), was also found to be increased (5). There is an ongoing debate regarding the clinical relevance of myeloid marker expression in T-cell ALL and whether their expression is a predictor of poor outcome $(3-5,10,11)$. Furthermore, the effect of CD34 expression on clinical outcome in T-cell ALL is controversial $(9,10)$ and remains to be elucidated.
Another surface antigen associated with poor prognosis in T-cell ALL is the CD56 (also referred to as neural cell adhesion molecule) surface antigen. CD56 is a marker for natural killer (NK) cells, but is also expressed in neoplastic myeloid, lymphoid, plasmacytoid dendritic and myeloma cells, as well as in a minority of $\mathrm{T}$ cells (7). Co-expression of myeloid markers together with CD34 and CD56 in T-cell ALL is seen more frequently $(6,7)$. To the best of our knowledge, this is the first report of aberrant co-expression of the NK cell marker CD56, the myeloid cell markers CD117 and CD33 and the stem cell marker CD34 in a patient with T-cell ALL. This appears to be associated with an unfavorable outcome, despite the use of intensive chemotherapy.

\section{References}

1. Van Vlierberghe P and Ferrando A: The molecular basis of T-cell acute lymphoblastic leukemia. J Clin Invest 122: 3398-3406, 2012.

2. Gamal AH: Classification of Acute Leukemia. University of Aden/Hematology Unit, Yemen, 2011.

3. Supriyadi E, Veerman AJ, Sutaryo, Purwanto I, Vd Ven PM and Cloos J: Myeloid antigen expression in childhood acute lymphoblastic leukemia and its relevance for clinical outcome in Indonesian ALL-2006 protocol. J Oncol 2012: 135186, 2012.

4. Suggs JL, Cruse JM and Lewis RE: Aberrant myeloid marker expression in precursor B-cell and T-cell leukemias. Exp Mol Pathol 83: 471-473, 2007.

5. Uckun FM, Sather HN, Gaynon PS, Arthur DC, Trigg ME, Tubergen DG, Nachman J, Steinherz PG, Sensel MG and Reaman GH: Clinical features and treatment outcome of children with myeloid antigen-positive acute lymphoblastic leukemia: A report from the Children's Cancer Group. Blood 90: 28-35, 1997.

6. Montero I, Rios E, Parody R, Perez-Hurtado JM, Martin-Noya A and Rodriguez JM: CD56 in T-cell acute lymphoblastic leukaemia: A malignant transformation of an early myeloid-lymphoid progenitor? Haematologica 88: ELT26, 2003.

7. Fischer L, Gökbuget N, Schwartz S, Burmeister T, Rieder H, Brüggemann M, Hoelzer D and Thiel E: CD56 expression in T-cell acute lymphoblastic leukemia is associated with non-thymic phenotype and resistance to induction therapy but no inferior survival after risk-adapted therapy. Haematologica 94: 224-229, 2009.

8. Vardiman JW, Thiele J, Arber DA, Brunning RD, Borowitz MJ, Porwit A, Harris NL, Le Beau MM, Hellström-Lindberg E, Tefferi A and Bloomfield CD: The 2008 revision of the World Health Organization (WHO) classification of myeloid neoplasms and acute leukemia: Rationale and important changes. Blood 114: 937-951, 2009.

9. Pui CH, Hancock ML, Head DR, Rivera GK, Look AT, Sandlund JT and Behm FG: Clinical significance of CD34 expression in childhood acute lymphoblastic leukemia. Blood 82: 889-894, 1993.

10. Vitale A, Guarini A, Ariola C, Mancini M, Mecucci C, Cuneo A, Pane F, Saglio G, Cimino G, Tafuri A, et al: Adult T-cell acute lymphoblastic leukemia: Biologic profile at presentation and correlation with response to induction treatment in patients enrolled in the GIMEMA LAL 0496 protocol. Blood 107: 473-479, 2006.

11. Bhushan B, Chauhan PS, Saluja S, Verma S, Mishra AK, Siddiqui S and Kapur S: Aberrant phenotypes in childhood and adult acute leukemia and its association with adverse prognostic factors and clinical outcome. Clin Exp Med 10: 33-40, 2010. 